\title{
Characterization of Leiomyomatoid Angiomatous Neuroendocrine Tumour (LANT)-like Tumour in the Myometrium with Histopathological Examination
}

\author{
TAKUMA HAYASHI ${ }^{1}$, TOMOYUKI ICHIMURA ${ }^{2}$, MARI KASAI ${ }^{2}$, KENJI SANO $^{3}$, \\ DORIT ZHARHARY ${ }^{4}$, TANRI SHIOZAWA ${ }^{1}$, NOBUO YAEGASHI ${ }^{5}$ and IKUO KONISHI ${ }^{6}$ \\ ${ }^{1}$ Department of Obstetrics and Gynecology, Shinshu University School of Medicine, Nagano, Japan; \\ ${ }^{2}$ Department of Obstetrics and Gynecology, Osaka City University Graduate School of Medicine, Osaka, Japan; \\ ${ }^{3}$ Department of Medical Laboratory, Shinshu University Hospital, Nagano, Japan; \\ ${ }^{4}$ SIGMA-Aldrich Israel, Rehovot, Israel; \\ ${ }^{5}$ Department of Obstetrics and Gynecology, Tohoku University School of Medicine, Miyagi, Japan; \\ ${ }^{6}$ National Hospital Organization Kyoto Medical Centre, Kyoto, Japan
}

\begin{abstract}
Leiomyomatoid angiomatous neuroendocrine tumour (LANT) is possibly a new disease entity that was reported as a dimorphic neurosecretory tumour with a leiomyomatous vascular component; it was found in the pituitary. We describe uterine LANT-like malignant tumour in a 45-year-old woman with uterine mesenchymal tumour, diagnosed clinically as uterine leiomyoma. She underwent laparoscopic myomectomy. The tumour consisted of hyalinized vasculature, containing factor VIII-positive endothelium and $\alpha$-smooth muscle actin-positive vascular smooth muscle cells, and stromal cells, expressing neuroadhesion molecules. Both vascular and stromal components diffusely expressed chromogranin A. Histopathological examinations of uterine LANT-like malignant tumour revealed the common characteristic abnormalities of malignant uterine mesenchymal tumours, i.e. leiomyosarcomas. From our research, defective expression of calponin $\mathrm{HI}$ and proteasome $\beta 9$ (PSMB9)/ $\beta 1 i$ is observed in uterine LANT-like malignant tumour similarly to immunopathological findings of uterine leiomyosarcoma. These findings meet the definition of uterine LANT-like malignant tumour, and the research findings of our clinical case suggest that LANT is a special type of neuroendocrine neoplasm and is not organ specific.
\end{abstract}

Correspondence to: Takuma Hayashi, Department of Obstetrics and Gynecology, Shinshu University School of Medicine, 3-1-1, Asahi, Matsumoto, Nagano 390-8621, Japan. Tel: +81 263372719, e-mail: yoyoyo224@hotmail.com

Key Words: LANT, PSMB9, calponin H1, leiomyosarcoma, mesenchymal tumour.
Leiomyomatoid angiomatous neuroendocrine tumour (LANT) was firstly reported as a new neoplastic category (1). The histopathological concept of LANT is that of a dimorphic neoplasm consisting of an admixture of neurosecretory cells and leiomyomatous stroma surrounding intratumoural vessels (1). The original clinical case was reported as a pituitary neoplasm. Histopathological studies with LANT revealed there to be two major tumour components (1). The first cell population comprised of cytokeratin-negative neuroendocrine cells positive for neuroadhesion molecules and chromogranin A as a serum marker of neuroendocrine tumours (1). The second constituent was a smooth muscle actin (SMA)-positive leiomyomatous vascular component associated with positivity for a cell-cell adhesion molecule, CD34, in endothelia (1). On the basis of this particular histopathological pattern and immunophenotype, our research group proposed the descriptive diagnosis of LANT and suggested that it may be a variant of a dimorphic pituitary neoplasm, possibly related to null cell adenoma. Because no additional reports of this entity have since been published, whether LANT is a pituitary-specific tumour or a type of soft-tissue tumour is unclear. Our research group reports here uterine LANT-like malignant tumour, but this one occurring in the uterus, and histopathological examinations of LANT revealed the common characteristic abnormalities of uterine mesenchymal malignant tumours, i.e. leiomyosarcoma (LMS). This dimorphic tumour contained both vascular and stromal components. We suggest that uterine LANT-like malignant tumour may be derived from neuroendocrine cells that may have differentiated into uterine smooth muscle cells under the influence of transforming growth factor- $\beta$ (TGF $\beta$ ). 


\section{Materials and Methods}

Tissue collection. A total of 51 patients aged between 32 and 83 years who were diagnosed with smooth muscle tumours in the uterus were selected from pathological files. Serial sections were cut from at least two tissue blocks from each patient for haematoxylin and eosin staining and immunostaining. All tissues were used with the approval of the Ethical Committee of Shinshu University (approval no.4737, no.150, no.M192) after obtaining written consent from each patient. The pathological diagnosis of human uterine mesenchymal tumours was performed using established criteria with some modifications $(2,3)$. Briefly, usual leiomyoma (LMA) was defined as a tumour exhibiting typical histological features with a mitotic index (MI) [obtained by counting the total number of mitotic figures (MFs) in 10 high-power fields (HPFs) ] of $<5$ MFs per $10 \mathrm{HPFs}$. Cellular LMA was defined as a tumour with significantly increased cellularity $(>2,000$ myoma cells/HPF) and a $\mathrm{MI}<5$, but without cytological atypia. Bizarre LMA was defined as a tumour either with diffuse nuclear atypia and a $\mathrm{MI}<2$, or with focal nuclear atypia and a $\mathrm{MI}<5$ without coagulative tumour cell necrosis. Smooth muscle tumour of uncertain malignant potential was defined as a tumour with no mild atypia and a $\mathrm{MI}<10$, but with coagulative tumour cell necrosis. LMS was diagnosed in the presence of a MI>10 with either diffuse cytological atypia, coagulative tumour cell necrosis, or both. Of the 113 uterine mesenchymal tumours, 52 cases were diagnosed as uterine LMA, three cases were bizarre LMA, 58 cases were uterine LMS, and one case was uterine LANT-like malignant tumour, which was obtained from Tokushima University School of Medicine. Protein expression studies with cervical epithelium and carcinoma tissues were performed using tissue arrays (uterine cancer tissues; AccuMax Array, Seoul, Korea). Details regarding tissue sections are indicated in the manufacturer's literature (AccuMax Array).

Immunohistochemistry. Our research group evaluated the characteristics of uterine LANT-like malignant tumour and uterine mesenchymal tumours by means of immunohistochemical (IHC) staining. IHC staining for calponin $\mathrm{H} 1$, caveolin 1, cyclin B1, cyclin E1, cytokeratin, desmin, endoglin, epidermal growth factor receptor (EGFR), oestrogen receptor (ER), Ki-67/MIB1, proteasome $\beta 9$ (PSMB9)/ $\beta 1 \mathrm{i}$, progesterone receptor (PR), $\alpha$ SMA, TP53, and vimentin was performed on serial tumour sections. Anti-calponin $\mathrm{H} 1$ was purchased from Bioss Inc. (Woburn, MA, USA). Antibodies for caveolin1, ER (ER1D5), Ki-67 (MIB-1), PR (PR10A), and TP53 (DO-1) were purchased from Immunotech (Marseille, France). Anti$\alpha$ SMA was purchased from Dako (Agilent Technologies Glostrup Denmark). Antibodies for endoglin, and EGFR were purchased from Santa Cruz Biotechnology, Inc. (Dallas, TX, USA). Antibodies for cyclin B1, cyclin E1, and vimentin, were purchased from Cell Signaling Technology, Inc. (Danvers, MA, USA). Antibodies for cytokeratin, and desmin were purchased from VLVbio (Hästholmsvägen Nacka, Sweden). Anti-human PSMB9/ $\beta 1$ 1i was produced by SIGMA-Aldrich collaboration Laboratory (SIGMAAldrich, Japan Science and Technology Agency and Shinshu University). IHC was performed using the avidin-biotin complex method previously described. Briefly, one representative $5-\mu \mathrm{m}$ tissue section was cut from a paraffin-embedded sample of the radical hysterectomy specimen from patients with human uterine LMS. Sections were deparaffinized and rehydrated in graded alcohol series. After the samples were washed with phosphate-buffered saline $(\mathrm{pH}$
7.4), the samples were incubated with normal mouse serum for 20 min. Sections were then incubated at room temperature for $1 \mathrm{~h}$ with primary antibody. After extensive washing, the samples were reacted for $60 \mathrm{~min}$ with adequate peroxidase-labeled secondary antibody (Histofine Simple Stain MAX-PO; Nichirei Bioscience, Tokyo, Japan). The immunoreaction was visualized, after removal of unbound secondary antibodies via incubation with diaminobenzidine (DAB)-hydrogen peroxidase solution. Immunostained samples were counterstained with hematoxylin and mounted with SUPER Mount (Matsunami Glass Industry Co, Osaka, Japan). Normal mesenchymal portions in the specimens were used as positive controls. Negative controls consisted of tissue sections incubated with normal rabbit IgG instead of the primary antibody. These studies were registered at Shinshu University in accordance with local guidelines (approval no. M192).

Sequencing of the catalytic domains of the Janus kinase 1 (JAK1), $J A K 2$ and signal transducer and activator of transcription 1 (STAT1) and genes and the promoter region of PSMB9/ $\beta 1$ i gene. To determine whether somatic mutations exist in the ATP-binding region or kinase activation domain of $J A K 1$ and $J A K 2$, in the promoter region of $P S M B 9 / \beta 1 i$ gene at Tyr701, or Ser727 of STAT1 in human uterine LMS, genomic DNA was isolated and direct sequencing was carried out. Genomic DNA was extracted from consecutive paraffin-embedded human uterine LMS tissue and normal myometrial tissue sections using microwave-based DNA extraction method for PCR amplification (4). To avoid contamination with normal myometrium or inflammatory cells, the tumour areas were confirmed using a haematoxylin and eosinstained glass slide as a template. The tumour tissues were scraped by razor-microdissection from consecutive paraffin-embedded tissue sections. The genomic DNA was subjected to polymerase chain reaction (PCR), and restricted DNA fragments for direct sequencing analysis were amplified using published oligonucleotide primers. PCR products were directly sequenced using a DYEnamic Terminator Cycle Sequencing Kit (Amersham-Biosciences, Piscataway, NJ, USA) with an ABI Prism 3100 Genetic Analyzer (Applied Biosystem, Foster City, CA, USA). The sequences of mutant $J A K 1$, JAK2, STAT1, and the promoter region of PSMB9/ $\beta 1 i$ gene derived from individual uterine LMS tissue sections are registered in the DNA Data Bank of Japan (Accession: AB219242, DJ055380, DJ055379, DJ055378, DJ055377, DJ055376). Details of primer sets for direct sequence analysis are indicated in Table I.

\section{Results}

During the course of an annual health examination, a healthy 45-year-old woman was found to be anaemic, and a gynaecologist found a uterine tumour causing hypermenorrhoea. Magnetic resonance imaging examination disclosed a myometrial mass of $60 \times 57 \times 59 \mathrm{~mm}$ with heterogeneous intratumoural signals. The radiological diagnosis was uterine LMA with partial degeneration. At the patient's request, laparoscopic myomectomy was performed. The soft, white tumour had a cauliflower-like surface, which was incompatible with the radiological diagnosis. Histologically, the tumour possessed two major components: The first, prominent vasculature with small lumina and hyalinized walls, and, the second, a cellular stromal component. Specifically, we noted 
Table I. Primer sets for direct sequence analysis.

\begin{tabular}{|c|c|c|c|}
\hline Target gene & Protein & Primer & Sequence \\
\hline \multirow[t]{6}{*}{ TP53 } & Tumor protein $\mathrm{p} 53$ & Forward & $5^{\prime}$-ccettcccagaaaacctacc-3' \\
\hline & & Reverse & 5 '-gcccaaagggtgaagaggaat-3 \\
\hline & & Forward & 5 '-gagagacgacagggctggt-3' \\
\hline & & Reverse & 5 -cactgacaaccaccttaacc-3, \\
\hline & & Forward & $5^{\prime}$-ccacaggtctccccaagg-3' \\
\hline & & Reverse & 5 '-agcaggaaagtgtgcag-3' \\
\hline \multirow[t]{12}{*}{ JAK1 } & Janus kinase 1 & Forward & 5 '-caccaaatcttta aaccggaccccagcctt-3' \\
\hline & & Reverse & 5 '-tacgatggggcttcctgataacagcac at-3' \\
\hline & & Forward & 5 '-atggctttctgtgctaaaatgaggagctcc-3' \\
\hline & & Reverse & 5 '-tccatcctgctcggtcttggggtctcgaat-3' \\
\hline & & Forward & 5 '-attcgagaccccaagaccgagcaggatgga-3, \\
\hline & & Reverse & 5'-tccactggattccaagattcccagtcacca-3', \\
\hline & & Forward & 5 '-tggtgactgggaatcttggaatccagtgga-3, \\
\hline & & Reverse & 5'-ggcggct catgaggtctcccaagctgggga-3' \\
\hline & & Forward & 5 -tccccagcttgggagacctcat gagccacc-3' \\
\hline & & Reverse & 5 '-ccgtaatggggatgccggggtcactgagct-3' \\
\hline & & Forward & 5 '-agctcagtgaccceggcatccccattacgg-3, \\
\hline & & Reverse & 5 -cagatcagctatgtggttacctccactctc-3' \\
\hline \multirow[t]{13}{*}{$J A K 2$} & Janus kinase 1 & Forward & 5 '-cagattatgggtaa tgattaaaggctccca-3' \\
\hline & & Reverse & 5 '-cacagcatttctccaacatctgacaaccaaacc-3, \\
\hline & & Forward & 5'-gacagtctgctaattccagctactagaa-3' \\
\hline & & Reverse & $5^{\prime}$-gc ctctcctctgggcattggcataagtcc-3' \\
\hline & & Forward & 5 '-atgaagcaaccgtgttgaagtagacattag-3' \\
\hline & & Reverse & 5 '-ccacgtggactataaccatgacta taagacc-3' \\
\hline & & Nested PCR & \\
\hline & & Forward & 5'-gaaactatttgagtttccetgtatcatttag-3' \\
\hline & & Reverse & 5 '-ctacaagcactccttaaaatgttg tagaaag-3, \\
\hline & & Forward & 5 '-gtaatttgcettgaaaactggtatttcc-3' \\
\hline & & Reverse & 5 '-gcataagtccagatcgttaagacattgtac- 3 ', \\
\hline & & Forward & 5 -gaagtagacatt aggaaatcatctagacg-3, \\
\hline & & Reverse & 5'-cactgttactgtaaatatagaaatggcaaac-3' \\
\hline \multirow[t]{9}{*}{ STAT1 } & Signal transducer and activator of transcription 1 & Forward & 5 '-cacttattgagagctacacacagg ccagcc-3' \\
\hline & & Reverse & 5 '-ggctggggacatgagaatcccatgagctgt-3' \\
\hline & & Forward & 5 -tgctgataggcagtaacacggggatctcaa-3' \\
\hline & & Reverse & 5 '-a ggaggctaagctgtctagaaacacagtag- 3 , \\
\hline & & Nested PCR & \\
\hline & & Forward & 5'-ttgagagctacacacaggccagccgtggt a-3' \\
\hline & & Reverse & 5 '-gggacatgagaatcccatgagctgtacttt-3' \\
\hline & & Forward & $5^{\prime}$-tgctgataggcagtaacacggggatctcaa-3' \\
\hline & & Reverse & 5 '-gtctaga aacacagtagaactttaatcccc-3' \\
\hline \multirow[t]{5}{*}{ PSMB9-promoter } & Proteasome subunit beta 9 & Forward & 5'-cgagaagctcagccatttaggggaaagcga-3', \\
\hline & & Reverse & $5^{\prime}$-cgccegcagcatccetgcaaggcaccgctc- $3^{\prime}$ \\
\hline & & Nested PCR & \\
\hline & & Forward & 5'-aagcgaaatcgaaagcggccgcetgct cac-3' \\
\hline & & Reverse & $5^{\prime}$-ctctcctcgccgcetggggcactggtttcc-3' \\
\hline
\end{tabular}

oval- or spindle shaped nuclei with fine chromatin and faint nucleoli, obscure cytoplasm, and very poor mitotic activity. All randomly obtained histopathological samples from five different paraffin blocks showed the same histopathological pattern.

Smooth muscle cells in a benign mesenchymal tumour, uterine LMA, markedly expressed $\alpha$ SMA and neuroadhesion molecule (CD56); however, no cell was positive for neuronspecific enolase, chromogranin A. Most cells of uterine
LANT-like malignant tumour diffusely express CD56 and chromogranin A (5). In addition, the cytological features of each major component were quite similar. Our research group demonstrated differential expression of several proteins in human uterine mesenchymal tumours and normal myometrium (Tables II-IV). IHC examination of uterine mesenchymal tumours demonstrated that although calponin $\mathrm{H} 1$ and PSMB9)/ $\beta 1 \mathrm{i}$ were found to be markedly expressed 
Table II. Differential expressions of proteasome subunit beta 9 (PSMB9/ $\beta 1 i)$ and calponin $H 1$ in human uterine mesenchymal tumours and uterine leiomyomatoid angiomatous neuroendocrine tumour (U. LANT)-like tumour. Staining scores for PSMB9/B1i expression and calponin H1 expression from results of immunohistochemical studies.

\begin{tabular}{|c|c|c|c|c|c|c|c|c|c|c|}
\hline & \multirow[t]{2}{*}{ Age, years } & \multirow[t]{2}{*}{$\mathrm{n}$} & \multicolumn{4}{|c|}{ PSMB9/ $\beta 1$ i expression, $n$} & \multicolumn{4}{|c|}{ Calponin $\mathrm{H} 1$ expression, $\mathrm{n}$} \\
\hline & & & - & $-/+$ & Focal + & +++ & - & $-/+$ & Focal + & +++ \\
\hline Normal myometrium & $32-83$ & 74 & & & & 74 & & & & 74 \\
\hline Leiomyoma & $33-83$ & 52 & & & & 52 & & & & 52 \\
\hline (Ordinally leiomyoma) & & $(30)$ & & & & & & & & \\
\hline (Cellular leiomyoma) & & (10) & & & & & & & & \\
\hline (Tumour of uncertain malignant potentialy) & & (12) & & & & & & & & \\
\hline Bizarre leiomyoma & $44,49,55$ & 3 & & & & 3 & & & & 3 \\
\hline Leiomyosarcoma & $32-83$ & 58 & 49 & 3 & 4 & 2 & 50 & 2 & 4 & 2 \\
\hline U.LANT-like tumour & 45 & 1 & 1 & & & & 1 & & & \\
\hline
\end{tabular}

-/+: Partially positive (5\% to $10 \%$ of cells stained); Focal+: Focally positive (focal or sporadic staining with fewer than $5 \%$ of cells stained); +++: diffusely positive (homogenous distribution with more than $90 \%$ of cells stained); - : negative, no stained cells.

in three types of uterine mesenchymal tumors and normal myometrium, loss of expression of calponin $\mathrm{H} 1$ and PSMB9/ $\beta 1 \mathrm{i}$ was observed in human uterine malignant mesenchymal tumour, i.e. uterine LMS (Figure 1, Tables II and III). It is likely that calponin $\mathrm{H} 1$ and PSMB9/ $\beta 1 \mathrm{i}$ are potential biomarkers which can distinguish LMS from other uterine mesenchymal tumours. Our research group therefore examined expression patterns of both proteins, calponin $\mathrm{H} 1$ and PSMB9/ $\beta 1 \mathrm{i}$ in uterine LANT-like malignant tumour. IHC examination demonstrated that although calponin $\mathrm{H} 1$ and PSMB $/ / \beta 1 \mathrm{i}$ were markedly expressed in normal myometrium, their loss of expression PSMB9/ $\beta 1 \mathrm{i}$ was observed in uterine LANT-like malignant tumour similarly to immunopathological findings of uterine LMS (Figure 1, Tables II and III). In sections of uterine LANT-like malignant tumour, the vascular structure was reportedly composed of factor VIII-, CD31-, and CD34-positive endothelial cells, and $\alpha$ SMA- and sarcomeric muscle actinpositive vascular smooth muscle cells $(5,6)$. Results for D240 , a lymphatic endothelial marker, were reportedly negative, which suggests that the vascular structure was not a lymphatic tumour such as lymphangiomyoma (7).

\section{Discussion}

Here, our research group presented histological and immunopathological characteristics of a complex, dimorphic neurosecretory tumour possessing a smooth muscle cell-rich vascular component and a population of stromal cells expressing neuronal differentiation molecules. On the basis of its particular histological aspects and immunepathological observations, we first ruled-out the possibility of a uterine LMA with a heterologous paraganglioma element (8). We also ruled out the possibility that the tumour was a glomangioma, perivascular epithelioid cell tumour, paraganglioma, solitary fibrous tumour, extragastrointestinal stromal tumour, or extragastrointestinal stromal tumour with neuroectodermal differentiation (9-14). Our histological examinations of the uterine LANT-like malignant tumour revealed the common characteristic abnormalities of LANT, which was reported as a pituitary neoplasm (1). Although the characteristics of the uterine tumour were indeed those of a LANT, we found two significant differences between the original LANT reported by Vajtai et al. (1) and our clinical case. Firstly, the original LANT was identified as a pituitary neoplasm, but our clinical case was of a uterine mesenchymal tumour. Soft-tissue tumours are known to appear in various organs, including the pituitary and uterus. Instead, our case here may have been a soft-tissue tumour with a neurosecretory phenotype. Therefore, we accepted the possibility that the tumour described here was a second clinical case of LANT. Secondly, in the original LANT report, chromogranin A and synaptophysin were predominantly detected in a "neurosecretory" component of the tumour. However, most tumour cells in uterine LANTlike malignant tumour expressed chromogranin A but not synaptophysin. Thus, tumour cells in the present clinical case were neuroendocrine regardless of their location, whether vascular or stromal. In the initial report, a few stromal "leiomyomatoid" cells appeared to express chromogranin A (1). Synaptophysin and chromogranin A, both of which are neuroendocrine markers, are localized in distinctive neurosecretory vesicles, the former predominantly in small transparent-looking vesicles and the latter in large densecored granules (15). It seems that part of the leiomyomatous stromal component of the pituitary LANT may have contained small, immature neuroendocrine vesicles. Recent study with electron microscopy demonstrated that the tumour 
Table III. Expression of oestrogen receptor (ER), progesterone receptor (PR), Ki-67, tumor protein p53 (TP53), proteasome subunit beta 9 (PSMB9), and calponin $\mathrm{H1}$ (Cal), and somatic mutations of TP53, Janus kinase 1 (JAK1), JAK2, signal transducer and activator of transcription 1 (STAT1), and PSMB9-promoter (PSMB9-pro.) in human uterine leiomyosarcoma.

\begin{tabular}{|c|c|c|c|c|c|c|c|c|c|c|c|c|c|c|c|c|}
\hline \multirow{2}{*}{$\begin{array}{l}\text { Patient } \\
\text { no. }\end{array}$} & \multirow{2}{*}{$\begin{array}{l}\text { Age, } \\
\text { years }\end{array}$} & \multicolumn{9}{|c|}{ Immunohistochemical staining } & \multicolumn{5}{|c|}{ Somatic mutations } & \multirow{2}{*}{$\begin{array}{c}\text { Follow-up } \\
\text { (months) }\end{array}$} \\
\hline & & TMN stage & MF & $\mathrm{CCN}$ & ER & PR & $\mathrm{Ki}-67$ & TP53 & PSMB9 & Cal. & TP53 & $J A K 1$ & $J A K 2$ & STAT1 & $P S M B 9$ pro & \\
\hline 1 & 37 & T4N1M0 & 97 & + & - & - & 3000 & +++ & - & - & SM & ND & ND & ND & ND & $\mathrm{D}(1)$ \\
\hline 2 & 58 & T3N0M0 & 24 & + & - & - & 3500 & + & $-1+$ & - & SM & ND & ND & ND & SM & D (23) \\
\hline 3 & 45 & T2N0M0 & 32 & + & $-1+$ & $-/+$ & 2150 & +++ & - & - & SM & SM & ND & SM & SM & D (24) \\
\hline 4 & 65 & T1N0M0 & 30 & + & $-1+$ & $-/+$ & 1700 & +++ & - & - & SM & SM & ND & ND & ND & $\mathrm{D}(20)$ \\
\hline 5 & 52 & T1N0M0 & 107 & + & - & + & 2600 & ++ & + & - & ND & SM & ND & ND & ND & D (13) \\
\hline 6 & 49 & T1N0M0 & 46 & + & - & - & 4300 & + & - & - & ND & ND & ND & ND & ND & D (24) \\
\hline 7 & 55 & T1N0M0 & 75 & + & - & - & 4000 & +++ & - & - & ND & ND & ND & SM & SM & D (18) \\
\hline 8 & 43 & T3N0M0 & 57 & + & + & - & 2000 & - & $-1+$ & $-/+$ & ND & ND & ND & ND & ND & $\mathrm{D}(10)$ \\
\hline 9 & 67 & T1N0M0 & 13 & + & - & $-/+$ & 1430 & - & - & - & ND & SM & ND & ND & ND & A (34) \\
\hline 10 & 67 & T1N0M0 & 37 & + & - & - & 2100 & - & - & - & ND & ND & ND & SM & SM & A (15) \\
\hline 11 & 51 & T1N0M0 & 93 & + & - & - & 4500 & - & - & - & ND & ND & ND & SM & ND & A (94) \\
\hline 12 & 48 & T1N0M0 & 14 & + & - & - & 900 & +++ & + & + & ND & ND & ND & ND & ND & A (58) \\
\hline 13 & 51 & T1N0M0 & 22 & + & $-1+$ & + & 450 & + & - & - & ND & SM & ND & ND & SM & A (34) \\
\hline 14 & 67 & T1N0M0 & 64 & + & - & + & 1450 & ++ & - & - & ND & ND & ND & ND & ND & A (15) \\
\hline 15 & 52 & T1N0M0 & 65 & + & - & - & 1780 & ++ & - & - & ND & SM & ND & SM & ND & D (23) \\
\hline 16 & 42 & T3N0M0 & 73 & + & - & - & 2130 & ++ & - & - & ND & ND & ND & ND & SM & A (21) \\
\hline 17 & 80 & T1N0M0 & 98 & + & - & - & 1980 & +++ & - & - & ND & SM & ND & ND & ND & D (19) \\
\hline 18 & 56 & T1N0M0 & 78 & + & - & - & 1860 & ++ & - & - & ND & ND & ND & ND & ND & $\mathrm{A}(11)$ \\
\hline 19 & 58 & T1N0M0 & 40 & + & - & - & 1750 & ++ & - & - & ND & ND & ND & ND & ND & A (10) \\
\hline 20 & 65 & T2N0M0 & 67 & + & - & - & 780 & +++ & - & - & ND & SM & ND & ND & SM & A (12) \\
\hline 21 & 45 & T1N0M0 & 52 & + & - & - & 1045 & ++ & - & - & ND & SM & ND & ND & SM & A (13) \\
\hline 22 & 57 & T2NOMO & 62 & + & - & - & 980 & ++ & $+/-$ & - & ND & SM & ND & ND & SM & $\mathrm{A}(11)$ \\
\hline 23 & 54 & $\mathrm{~T} 1 \mathrm{~N} 1 \mathrm{M} 0$ & 54 & + & - & - & 860 & +++ & - & - & ND & ND & ND & ND & SM & A (02) \\
\hline
\end{tabular}

Ki-67: Ki-67-positive cell number/10 high-power fields; SM: somatic mutation; ND: not detected; D: died of disease; A: alive; MF: mitotic figure/10 high-power fields; CCN: coagulative cell necrosis. -: Negative, no stained cells; +/-: partial expression; +: low expression; ++: medium expression; +++ : high expression.

cells in uterine LANT-like malignant tumour contained predominantly chromogranin A-positive, dense-cored neurosecretory granules (5). This finding suggests that the diffuse distribution of tumour cells with a neurosecretory phenotype in uterine LANT-like malignant tumour is consistent with the features of the first reported LANT. In addition, other research facilities reported that significantly elevated serum chromogranin A level was detected in two of 12 patients with uterine LMA without any histological observations $(16,17)$.

The histogenesis of this newly-reported type of neoplasia is not clearly understood. Recent experimental studies shown that a group of neuroendocrine neoplasms represented florid vascular proliferation resulting from angiogenic factors produced by the tumour cells themselves $(18,19)$. Differently from this type of florid vascular proliferation, the vascular component of uterine LANT-like malignant tumour consisted of endothelial cells and vasculature-related smooth muscle cells with neurosecretory features. On the basis of this specific feature, our research group proposes that uterine LANT-like malignant tumour may be derived from neurosecretory cells that differentiated into smooth muscle cells in an angiogenic microenvironment. At present, the nature of a putative neurosecretory cell with the potential to differentiate into smooth muscle cells is poorly understood. However, our previous research finding of TGF $\beta$-positive endothelial cells in uterine LANT-like malignant tumour tissue offers support for this differentiation hypothesis because this molecule is crucial for differentiation of vascular smooth muscle cells, as well as for cell proliferation during tumour angiogenesis $(5,6)$. The physiological significance of calponin $\mathrm{H} 1$ and PSMB9/ $/ 31 \mathrm{i}$ in sarcomagenesis of uterine malignant mesenchymal tumour, LMS, is reportedly demonstrated by our research findings. Both factors, calponin H1 and PSMB9/ $\beta 1 \mathrm{i}$, are useful as biomarkers to distinguish human uterine LMS from other uterine mesenchymal tumours (20-22). Our research findings highlight the possibility that calponin $\mathrm{H} 1$ and PSMB9/ $/ 31 \mathrm{i}$ are potential diagnostic biomarkers which can distinguish uterine LANT-like malignant tumour from other uterine mesenchymal tumours. These factors may play key roles in tumorigenesis of uterine LANT-like malignant tumour. 


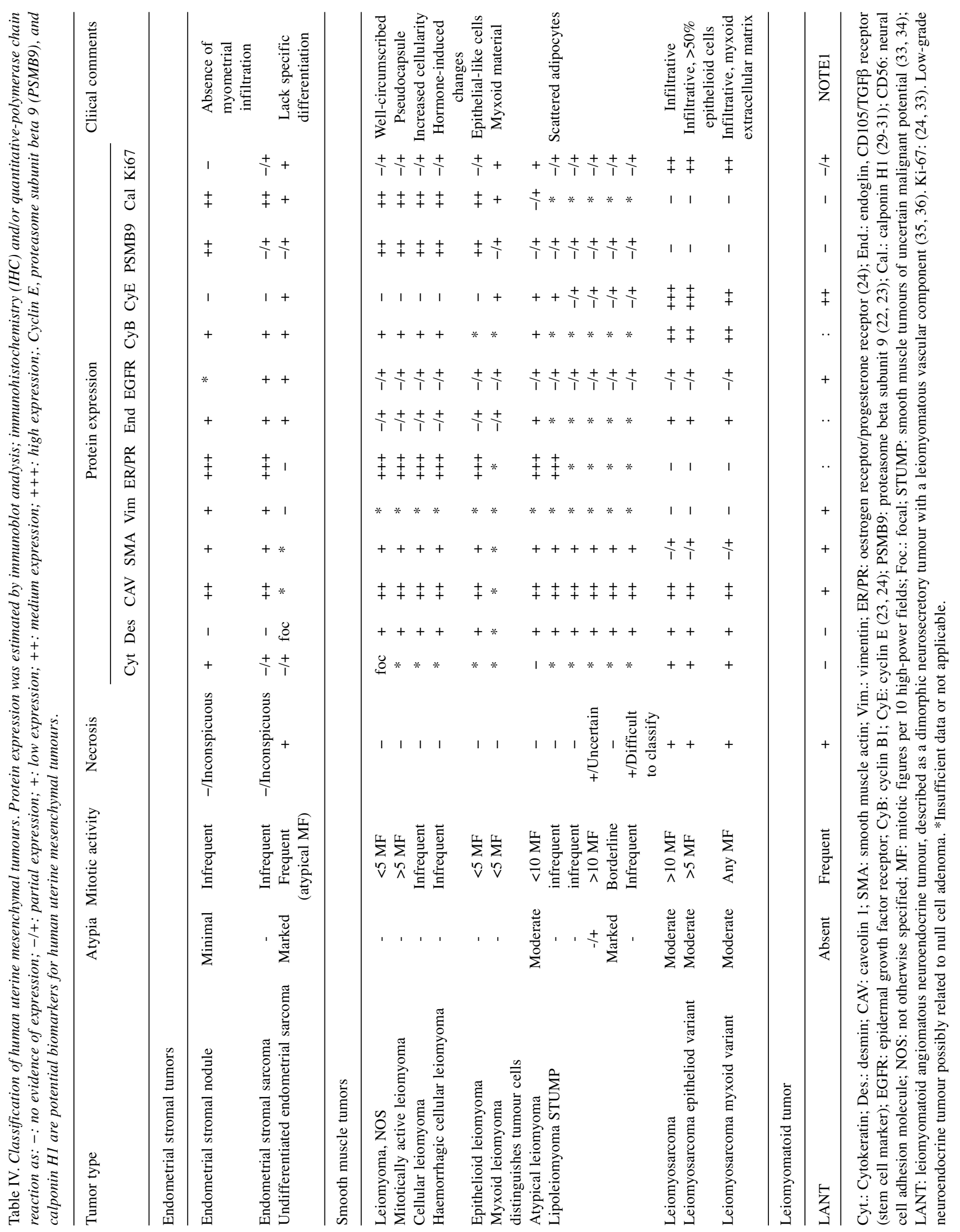




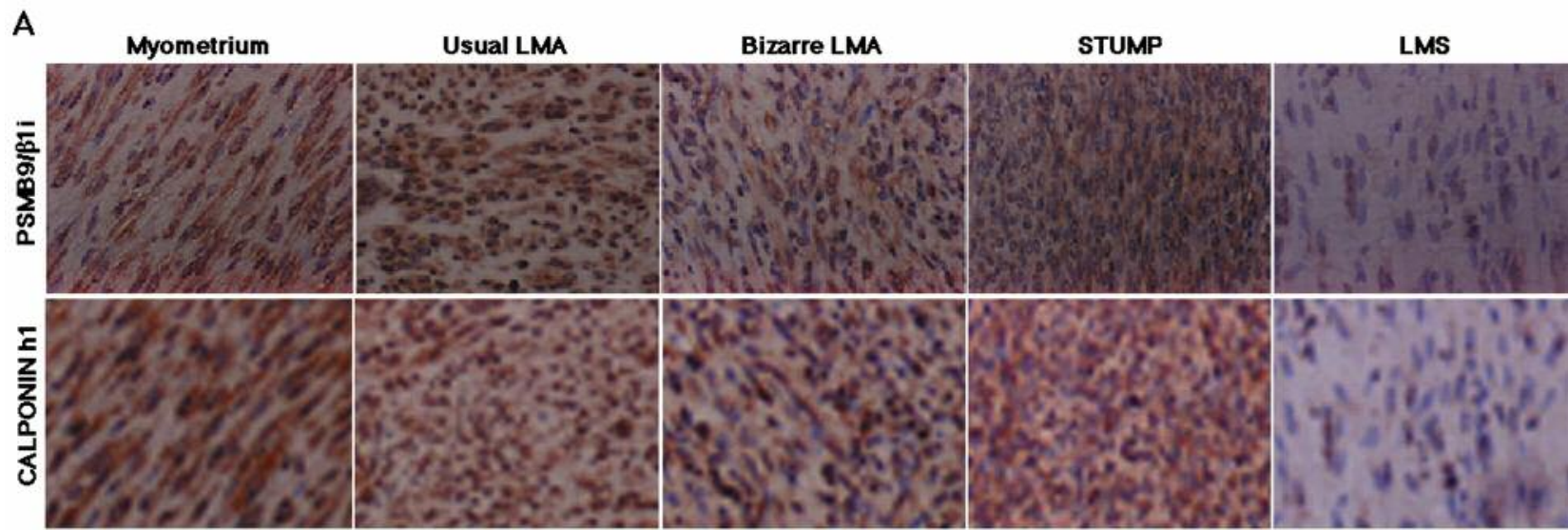

B

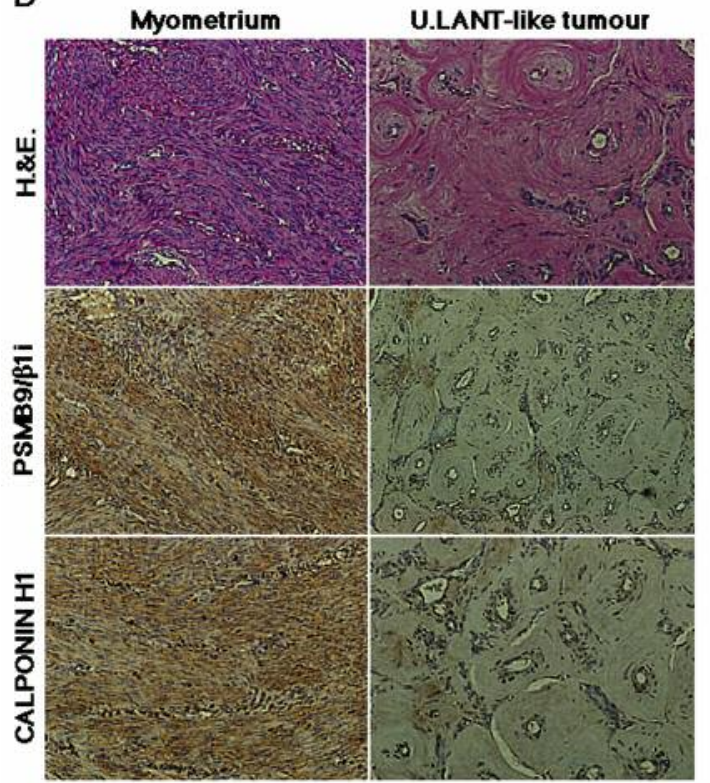

Figure 1. Differential expression of proteasome $\beta 9$ (PSMB9/ $\beta 1 i)$ and calponin $H 1$ in human normal myometrium, several mesenchymal tumour types and uterine leiomyomatoid angiomatous neuroendocrine tumour (U.LANT)-like malignant tumour. A: Immunohistochemistry of PSMB9/B1i and calponin H1 in normal myometrium, usual leiomyoma (LMA), bizarre LMA, smooth muscle tumour of uncertain malignant potential (STUMP) and uterine leiomyosarcoma (LMS) tissues located in same tissue and uterine LANT-like malignant tumour. For all samples, 5- $\mu \mathrm{m}$ sections of tissues specimens were stained with antiPSMB9/ß1i antibody revealed by peroxidase-conjugated anti-rabbit IgG antibody. B: IHC studies individually performed at several medical facilities revealed a marked loss in the ability to induce the expression of PSMB9/B1i and calponin H1 in human uterine LMS tissues and human uterine LANT-like malignant tumour tissue compared to that in normal human myometrium located in the same tissue section, as well as to that in LMA tissues. Normal myometrium: 58 cases, usual LMA: 50 cases, bizarre LMA: three cases, LMS: 56 cases, uterine LANT-like malignant tumour: one case. The analyses were performed three times with similar results.

In summary, we report a uterine LANT-like malignant tumour arising in the myometrium. Findings for this clinical case suggest the possibility that LANT is not organ-specific and may instead be a type of soft-tissue tumour composed of neuroendocrine cells with the potential to differentiate into a leiomyomatous phenotype in a TGF $\beta$-dependent manner. To confirm this hypothesis, additional examinations should be performed via immunohistological analyses.

\section{Disclosure}

The Authors report no conflicts of interest.

\section{Acknowledgements}

The Authors appreciate the donation of sections of human uterine LANT-like tissue by Dr. Naomi Sakashita, Department of Pathology, Tokushima University School of Medicine. This work was supported by grants from the Ministry of Education, Culture, Science and Technology, the Japan Science and Technology Agency (JST), the Foundation for the Promotion of Cancer Research, Kanzawa Medical Research Foundation, and The Ichiro Kanehara Foundation.

\section{References}

1 Vajtai I, Sahli R, Kappeler A, Christ ER and Seiler RW: Leiomyomatoid angiomatous neuroendocrine tumor (LANT) of the pituitary: a distinctive biphasic neoplasm with primitive secretory phenotype and smooth muscle-rich stroma. Acta Neuropathol 111: 278-283, 2006.

2 Kurma RJ: Pathology of the Female Genital Tract, Fourth Edition. New York, Springer-Verlag 4: 499, 2001.

3 Diagnostic Criteria for LMS, Adapted from 2003 WHO Guidelines: World Health Organization Classification of Tumours: Pathology and Genetics, Pathology and Genetics of Tumours of the Breast and Female Genital Organs. IARC Press, France, 2003. 
4 Banerjee SK, Makdisi WF, Weston AP, Mitchell SM and Campbell DR: Microwave-based DNA extraction from paraffinembedded tissue for PCR amplification. BioTechniques 18: 768774,1995

5 Sakashita N, Yamada M, Nakagawa T, Yamasaki H and Takeya M: A leiomyomatoid angiomatous neuroendocrine tumor of the myometrium: case study with ultrastructural analysis. Hum Pathol 39(5): 788-792, 2008.

6 Bryan BA and D'Amore PA: Pericyte isolation and use in endothelial/pericyte coculture models. Methods Enzymol 443: 315-331, 2008.

7 Hansen T, Katenkamp K, Bittinger F, Kirkpatrick CJ and Katenkamp D: D2-40 labeling in lymphangiomyoma/ lymphangiomyomatosis of the soft tissue: further evidence of lymphangiogenic tumor histogenesis. Virchows Arch 450: 449-453, 2007.

8 Naidoo P: Vaginal leiomyoma with heterologous paragangliomatous elements. Int J Surg Pathol 8: 359-365, 2000.

9 Piura B and Shaco-Levy R: Pedunculated aggressive angiomyxoma arising from the vaginal suburethral area: case report and review of literature. Eur J Gynaecol Oncol 26(5): 568-571, 2005

10 Vang R and Kempson RL: Perivascular epithelioid cell tumor ('PEComa') of the uterus: a subset of HMB-45-positive epithelioid mesenchymal neoplasms with an uncertain relationship to pure smooth muscle tumors. Am J Surg Pathol 26: 1-13, 2002.

11 Brustmann H: Paraganglioma of the vagina: report of a case. Pathol Res Pract 203(3): 189-192, 2007.

12 Strickland KC, Nucci MR, Esselen KM, Muto MG, Chopra S, George S and Howitt BE: Solitary fibrous tumor of the uterus presenting with lung metastases: A case report. Int $\mathbf{J}$ Gynecol Pathol 35(1): 25-29, 2016.

13 Zhu X, Fei J, Zhang W and Zhou J: Uterine leiomyoma mimicking a gastrointestinal stromal tumor with chronic spontaneous hemorrhage: A case report. Oncol Lett 9(6): 2481-2484, 2015.

14 Perez-Atayde AR, Shamberger RC and Kozakewich HW: Neuroectodermal differentiation of the gastrointestinal tumors in the Carney triad. An ultrastructural and immunohistochemical study. Am J Surg Pathol 17: 706-714, 1993.
15 Wiedenmann B and Huttner WB: Synaptophysin and chromogranins/secretogranins-widespread constituents of distinct types of neuroendocrine vesicles and new tools in tumor diagnosis. Virchows Arch B Cell Pathol Incl Mol Pathol 58: 95-121, 1989.

16 Peters-Engl C, Buxbaum P, Ogris E, Sevelda P and Medl M: TATI (tumor-associated trypsin inhibitor) and cancer antigen 125 (CA 125) in patients with early-stage endometrial cancer. Anticancer Res 18(6B): 4635-4639, 1998.

17 Tsao KC, Hong JH, Wu TL, Chang PY, Sun CF and Wu JT: Elevation of CA 19-9 and chromogranin A, in addition to CA 125 , are detectable in benign tumors in leiomyomas and endometriosis. J Clin Lab Anal 21: 193-196, 2007.

18 Akbulut M, Zekioglu O, Terek MC and Ozdemir N. Florid vascular proliferation in mature cystic teratoma of the ovary: case report and review of the literature. Tumori 95(1): 104-107, 2009.

19 Schürch C, Birrer M, Estella I, Kappeler A, Hewer E and Vajtai I. "Leiomyomatoid angiomatous neuroendocrine tumor" (LANT) of the pituitary reflects idiosyncratic angiogenesis in adenomas of the gonadotroph cell lineage. Pathol Res Pract 209(3): 155160, 2013.

20 Hayashi T and Faustman D: Development of spontaneous uterine tumors in low molecular mass polypeptide-2 knockout mice. Cancer Res 62: 24-27, 2002.

21 Hayashi T, Horiuchi A, Sano K, Hiraoka N, Kasai M, Ichimura T, Nagase S, Ishiko O, Kanai Y, Yaegashi N, Aburatani H, Shiozawa T and Konishi I: Potential role of LMP2 as tumorsuppressor defines new targets for uterine leiomyosarcoma therapy. Sci Rep 1: 180, 2011

22 Hayashi T, Horiuchi A, Sano K, Hiraoka N, Kasai M, Ichimura T, Nagase S, Ishiko O, Kanai Y, Yaegashi N, Aburatani H, Shiozawa T, Tonegawa S and Konishi I: Potential role of LMP2 as an anti-oncogenic factor in human uterine leiomyosarcoma: morphological significance of calponin H1. FEBS Lett 586(13): 1824-1831, 2012.
Received December 26, 2016

Revised March 7, 2017

Accepted March 10, 2017 